\title{
Place of Delivery Among Antenatal Clinic Attendees at a Rural Community in North Western Nigeria
}

\section{Takai IU, Ali Gombe H, Attah RA, Yakasai IA.}

Department of Obstetrics and Gynaecology, Bayero University Kano/Aminu Kano Teaching Hospital, Kano Nigeria.

doi)

https://doi.org/10.46912/jbrcp.165

\section{*Correspondence}

Attah RA : attahraph@yahoo.com

\begin{tabular}{|l|l|}
\hline $\begin{array}{l}\text { Article } \\
\text { information }\end{array}$ & $\begin{array}{l}\text { Date Submitted: 23/4/2020. } \\
\text { Date Accepted: 5/6/2020 } \\
\text { Date Published: June, 2020 }\end{array}$ \\
\hline
\end{tabular}

\begin{abstract}
In developing countries, most deliveries take place without a skilled birth attendance. This lack of skilled birth attendance could be considered as one of the major factors contributing to maternal and neonatal morbidity and mortality. The use of facility-based delivery system helps to reduce various complications during childbirth, which may be affected by social and cultural norms among several other factors. This study was to assess the proportion of pregnant women delivering at home and the role of socioeconomic and demographic factors affecting the choice of place of delivery among pregnant women attending antenatal, postnatal and Immunization clinic at Rano General Hospital, Kano. This is a cross sectional study carried out between September 2018 to November 2018 among 310 pregnant women who had at least delivered once and are attending antenatal care, post-natal or immunization clinic at the General hospital in Rano local government area of Kano state within the study period. Data was collected using interviewer administered questionnaire which was interpreted to those participants who cannot understand English language. Data obtained was entered into excel spread sheet 2018 and subsequently analyzed using SPSS 2016 version 20. Multivariate regression methods were used for measuring the associations between socio-demographic variables and place of delivery. About 310 questionnaires were distributed of which 100\% retrieval rate was achieved. A total of 281 (90.6\%) received antenatal services at least once during their previous pregnancy among which 183 (59.03\%) of them had home delivery. The respondents were between the ages of 18-37years with the mean age of 24.9 \pm 5.1 years. Minimum age of the respondents was 18 years, while the maximum age was 37 years. The main reasons for home delivery were, previous delivery was at home and complication free, short interval between onset of labor and delivery and also husband and mother in-law's decision. This study has shown that there is still high rate of home delivery among antenatal clinic attendees. This home delivery is usually preferred to hospital delivery by their husbands and mother in-laws as they consider it to be safe and more convenient. There is therefore need to educate women on early signs of labor and address the importance of health care delivery to prevent complications which may increase the maternal mortality rate.
\end{abstract}

Keywords: Antenatal, Home delivery, Hospital delivery. 


\section{BACKGROUND}

In developing countries, specifically in sub-Saharan Africa, many women do not have the good fortune to be attended by skilled personnel during childbirth, which could be considered as one of the major factors leading to maternal and neonatal morbidity and mortality. ${ }^{1}$ In the continuum of maternal health care, antenatal care, institutional/skilled attendance at delivery and postnatal care are important milestones required to achieve optimum maternal and child health. ${ }^{2}$ These elements of care are expected to be provided in order to impact maximum benefit and the provision of these elements of care in a comprehensive and continuum pattern of care during pregnancy, child birth and postpartum period has been argued to reduce maternal and child (neonatal) death. ${ }^{2}$ There were an estimated 358,000 maternal deaths in the world and approximately 800 women worldwide die every day during pregnancy and childbirth, ${ }^{3,4}$ The developing countries like ours, accounted for about $99 \%$ of maternal mortality, ${ }^{3,4,5}$ though the figures have been difficult to measure accurately ranging from 600-999 per 100,000 live births. ${ }^{1}$ Nigeria has continued to witness a high maternal mortality ratio, with huge variation across its region. ${ }^{1}$ There is a 1 in 13 chance of a woman dying during pregnancy, ${ }^{1}$ in the sub-Saharan region, home delivery among women of child bearing age is widespread and the use of reproductive health services still remains low. ${ }^{1}$ A study based on 48 Demographic and Health Survey (DHS) found that world-wide about half of the birth occurred at home, moreover in South and South-East Asia women from poor household had higher levels of home delivery compared to women in Sub-Saharan Africa. ${ }^{6}$ Maternal mortalities mainly occur during labor, delivery or within the first 24 hours after Childbirth. ${ }^{4} \mathrm{An}$ analysis of the causes of maternal deaths in Africa shows that most of these deaths are as a result of direct obstetric complications notably, hemorrhage, hypertension, sepsis and obstructed labor that usually occur around the time of delivery. ${ }^{4,5}$ Access to proper medical care and hygienic conditions during delivery can reduce the risk of complications and infections that may lead to death or serious illness for the mother and or the baby. ${ }^{6}$ The World Health Organization (WHO) therefore recommends delivery by a skilled birth attendant (SBA) in reducing deaths among pregnant women and neonates. ${ }^{5}$ The proportion of skilled health professionals available at the time of delivery is also one of the indicators for monitoring progress towards the Millennium Development Goal of improving maternal health. ${ }^{4}$ In Sub-Saharan Africa, uptake of skilled delivery services in healthcare facilities is low compared to other parts of the world. ${ }^{4}$ Nigeria Demographic and Health survey indicates that in 2018 only $56 \%$ of rural women received skilled antenatal care and only $29 \%$ were delivered by skilled birth attendant compared to $66 \%$ of urban women. ${ }^{6}$ By contrast a large proportion of rural women (77\%) throughout the country delivered at home or in the home of traditional birth attendants compared to $37 \%$ of urban women. ${ }^{6}$

In another study in Nigeria, only 35\% (25\% in rural and $60 \%$ in urban areas) of pregnant women use delivery services at healthcare facilities. ${ }^{4}$ The attendance of ANC and delivery in a facility by a trained birth assistance are far lower in Nigeria than most other African countries. ${ }^{7}$ In Sub-Saharan Africa, overall $75 \%$ had at least one ANC attendance, $48 \%$ had 4 or more ANC visits and $48 \%$ of deliveries were supported by skilled birth attendance. ${ }^{7}$ In a study by Idris et al reported that while $98 \%$ new mothers in Northern Nigeria attended ANC services at a health facility, only $24 \%$ of them actually delivered at a healthcare facility. ${ }^{8}$ The main barriers of healthcare facility identified in their study were no complications with previous delivery $(57 \%)$ and negative attitudes of healthcare providers $(24 \%) .{ }^{8}$ Different countries utilize different strategies and activities to increase facility delivery like elimination of user fees, community-based health insurance schemes, condition cash transfers, the establishment of birth centers, provision of incentives and birth preparedness packages. ${ }^{6}$

Kano state where this study was done enjoys free maternity services. It is therefore necessary to look at the impact of this free maternity care on hospital delivery among antenatal clinic attendees. Place of delivery is a crucial factor which affects the health and well-being of both the mother and the new born, 'therefore it is essential to explore the reasons for home delivery with the aim of encouraging hospital based delivery to reduce maternal and neonatal morbidity and mortality.

The aim of this study is to assess the proportion of home delivery and factors preventing pregnant women from utilizing the hospital or other healthcare facilities as their place of choice for delivery even after accessing ANC service. Also, to determine the socio-economic, demographic, cultural and obstetrics factors such as 
maternal age and parity, women and husbands' educational status, occupation and husbands' employment and income, health insurance scheme as predictors of health facility delivery by women at Rano General hospital, Kano.

\section{MATERIALS AND METHODS}

This was a cross sectional study carried out within 12 weeks between October 2018 to November 2018 in Rano General Hospital Kano. It is a 107 bedded hospital accredited by the West African College of surgeons as a rural posting General hospital for Resident doctors. The hospital renders a 24-hour medical, surgical and laboratory services which runs all the basic investigations. In addition, there is an X-RAY Unit and Ultrasound machine manned by a Radiology Technician. The facilities also has accommodation for residents doing their rural posting. The residents are supervised by a consultant from Aminu kano teaching hospital(AKTH), on weekly rotational basis.

Rano is a local Government Area of Kano State with its administrative headquarters in the town of Rano. Rano LGA is in the southern senatorial district of Kano State and is also a federal constituency alongside Bunkure and Kibiya LGA. It has an area of $520 \mathrm{~km}^{2}$ and a population of 145,439 as at 2006 census. The LGA is bounded to the north by Garun Mallam and Bunkure LGA, to the south by Tudun Wada LGA, and to the west by Bebeji LGA. About 100 pregnant women come for booking and another 240 women are seen weekly for their follow-up clinic.

The inclusion criteria were booked pregnant women attending ANC, postnatal clinic and immunization clinic who had previous vaginal delivery while the exclusion criteria involve those with previous abdominal delivery in their last delivery, un-booked patients and those not willing to participate in the study. The patients were recruited by convenient sampling technique and were counseled about the study and were allowed to give a written consent. Clinical assistants assisted in some of the distribution and interpretation of the Questionnaires in Hausa language.

The sample size of 310 women was computed using the Cochrane formula for cross sectional study, $\mathrm{z}^{2} \mathrm{pq} / \mathrm{d}^{2}$; where $\mathrm{n}=$ sample size, $\mathrm{z}=$ degree of accuracy required $=1.96, \mathrm{~d}=$ marginal error $5 \%(0.05)$ and $\mathrm{p}=$ the proportion used was $74.1 \%$ from previous study in Bagwai ${ }^{9}$ with $10 \%$ non- response rate at $95 \%$ confidence interval. Data necessary for the study was collected using interviewer administered questionnaire with open and closed ended questions. About 30 questionnaires were filled every week and 310 within 12 weeks. Ethical clearance was obtained from the ethical committee of Kano state ministry of health. The study was carried out in accordance with declaration of Helsinki 2013.

\section{Data Analysis}

Data obtained was entered into excel spread sheet 2018 and subsequently analyzed using IBM SPSS 2016 statistical version 20 (New York, USA) by Chi-square tests analysis. $\mathrm{P}<0.05$ was considered statistically significant. Multivariate regression methods were used to determine the role of socio-demographic variables and place of delivery.

\section{RESULTS}

Table 1 shows the socio-economic and demographic factors of the respondents with the age categorized in tables and figure below. The minimum age of the respondents was 18 years, while the maximum age was 37 years, with a mean of $24.9 \pm 5.1$ years. Majority of the respondents $304(98.1 \%)$ were Muslim while only $6(1.9 \%)$ were Christians and $82.9 \%$ were Hausas by tribe. Almost all the women were married except for $3(0.97 \%)$ who were divorcee.

One hundred and fifty-one $(48.7 \%)$ of the respondents have no formal education, $72(23.2 \%)$ attended primary school, $72(23.2 \%)$ have attended secondary school, and only fifteen $(4.9 \%)$ of the respondent have post-secondary education. Majority of the spouses 142 (45.8\%) had no formal education. One hundred and thirty (41.9\%) attended secondary and post-secondary education while $38(12.3 \%)$ have only primary education.

Majority of the respondents $270(87.1 \%)$ were unemployed. only 40 (12.9\%) were gainfully employed. Whereas, majority of respondent's spouses were engaged in farming $104(33.6 \%)$, since the area is blessed with dams and rivers were irrigation is actualized, while 96 $(31.0 \%)$ are traders. Sixty-four $(20.6 \%)$ were civil servants, $27(8.7 \%)$ were engaged in tailoring business while only $19(6.1 \%)$ among them were hawkers.

The mean income is N44018.75 \pm 27100.8 , with a Range 
Table I. Socio-economic and demographic factors of the respondents

\begin{tabular}{|c|c|c|c|c|c|}
\hline \multirow[t]{2}{*}{ Variables } & \multicolumn{2}{|c|}{ Prev. Place of delivery } & \multirow[t]{2}{*}{ Total } & \multirow[t]{2}{*}{$\mathbf{X}^{2}$} & \multirow[t]{2}{*}{ P-value } \\
\hline & Home n (\%) & Hospital n (\%) & & & \\
\hline \multicolumn{6}{|l|}{ Age group: } \\
\hline $18-22$ & $71(36.8)$ & $61(52.1)$ & $132(42.6)$ & 13.123 & 0.004 \\
\hline $23-27$ & $46(23.8)$ & $27(23.1)$ & $73(23.5)$ & & \\
\hline $28-32$ & $54(28.0)$ & $22(18.8)$ & $76(24.5)$ & & \\
\hline $33-37$ & $22(11.4)$ & $7(6.0)$ & $29(9.4)$ & & \\
\hline \multicolumn{6}{|l|}{ Mean: } \\
\hline \multicolumn{6}{|l|}{ Religion: } \\
\hline Islam & $193(100.0)$ & $111(94.9)$ & $304(98.1)$ & 9.292 & 0.004 \\
\hline Christianity & $0(0.0)$ & $6(5.1)$ & $6(1.9)$ & & \\
\hline \multicolumn{6}{|l|}{ Ethnicity: } \\
\hline Hausa & $159(82.4)$ & $98(85.0)$ & $257(82.9)$ & 12.691 & 0.006 \\
\hline Fulani & $32(16.6)$ & $13(10.2)$ & $45(14.5)$ & & \\
\hline Kanuri & $2(1.0)$ & $0(0.0)$ & $2(0.6)$ & & \\
\hline Igbo & $0(0.0)$ & $4(3.1)$ & $4(1.3)$ & & \\
\hline Yoruba & $0(0.0)$ & $2(1.6)$ & $2(0.7)$ & & \\
\hline \multicolumn{6}{|l|}{ Marital status: } \\
\hline Married & $180(98.4)$ & $127(100)$ & $307(99.0)$ & 1.993 & 0.280 \\
\hline Divorced & $3(1.6)$ & $0(0.0)$ & $3(1.0)$ & & \\
\hline \multicolumn{6}{|l|}{ Educational level: } \\
\hline Primary & $60(31.1)$ & $12(10.3)$ & $72(23.2)$ & 11.441 & 0.009 \\
\hline Secondary & $46(23.8)$ & $26(22.2)$ & $72(23.2)$ & & \\
\hline Tertiary & $6(3.1)$ & $9(7.7)$ & $15(4.9)$ & & \\
\hline No formal edu & $81(42.0)$ & $70(59.8)$ & $151(48.7)$ & & \\
\hline \multicolumn{6}{|l|}{ Spouse edu status: } \\
\hline Primary & $21(11.5)$ & $17(13.4)$ & $38(12.3)$ & 35.712 & 0.000 \\
\hline Secondary and above & $51(27.8)$ & $79(62.2)$ & $130(43.8)$ & & \\
\hline No formal edu & $111(60.7)$ & $31(24.4)$ & $142(45.8)$ & & \\
\hline \multicolumn{6}{|l|}{ Employment: } \\
\hline Employed & $20(10.9)$ & $20(17.0)$ & $40(12.9)$ & 2.031 & 0.169 \\
\hline Self employed & $163(89.0)$ & $107(31.3)$ & $270(87.1)$ & & \\
\hline \multicolumn{6}{|l|}{ Spouse occupation: } \\
\hline Employed & $26(14.2)$ & $38(29.9)$ & $64(20.6)$ & 12.954 & 0.000 \\
\hline Self employed & $157(85.8)$ & $89(70.1)$ & $246(79.4)$ & & \\
\hline \multicolumn{6}{|l|}{ Family income: } \\
\hline $5,000-19,999$ & $17(7.5)$ & $5(5.9)$ & $22(7.1)$ & 36.632 & $* * * * *$ \\
\hline $20,000-39,999$ & $98(43.4)$ & $30(35.7)$ & $128(41.3)$ & & \\
\hline $40,000-59,999$ & $78(34.5)$ & $34(40.5)$ & $112(36.1)$ & & \\
\hline $60,000-79,999$ & $11(4.9)$ & $7(8.3)$ & $18(5.8)$ & & \\
\hline $80,000-99,999$ & $10(4.4)$ & $4(4.8)$ & $14(4.5)$ & & \\
\hline$>100,000$ & $12(5.3)$ & $4(4.8)$ & $16(5.2)$ & & \\
\hline Mean, SD, Range & $\begin{array}{l}\text { N44018.75 } \pm 2 \\
\text { Range N1450 }\end{array}$ & & & & \\
\hline \multicolumn{6}{|l|}{ Family support: } \\
\hline Yes & $177(96.7)$ & $123(96.9)$ & $300(96.8)$ & 0.000 & 1.000 \\
\hline No & $6(3.3)$ & $4(3.1)$ & $10(3.2)$ & & \\
\hline \multicolumn{6}{|l|}{ Family Type: } \\
\hline Nuclear & $84(43.5)$ & $70(59.8)$ & $154(49.7)$ & 11.620 & 0.001 \\
\hline Extended & $109(56.5)$ & $47(40.2)$ & $156(50.3)$ & & \\
\hline \multicolumn{6}{|l|}{ Parity: } \\
\hline $1-3$ & $81(42.0)$ & $77(65.8)$ & $158(51.0)$ & 11.549 & 0.003 \\
\hline $4-6$ & $67(34.7)$ & $34(29.1)$ & $101(32.5)$ & & \\
\hline $7+$ & $45(23.3)$ & $6(5.1)$ & $51(16.5)$ & & \\
\hline
\end{tabular}


of N14500.

Out of the respondents, $154(49.7 \%)$ were in a nuclear family, while $156(50.3 \%)$ were in an extended family setting. Majority of the respondents $148(47.7 \%)$ had 1-3 children, 101(32.6\%) had 4-6 children, while 61 (19.7\%) having $>6$ children. The mean parity was $1.7 \pm 0.8$

Table 2: Shows some of the determinant of home delivery from previous ANC.

Antenatal attendance in previous pregnancy was seen in majority of the respondents $281(90.6 \%)$ while only 29 $(9.4 \%)$ with no previous antenatal attendance.

For those who had ANC in the previous pregnancy, 136 (48.4\%) booked at their $2^{\text {nd }}$ trimester, $81,(28.8 \%)$ at their $3^{\text {rd }}$ trimester, while only $64(22.8 \%)$ attended antenatal from their $1^{\text {st }}$ trimester. Majority $208(74.0 \%)$ had just 1-2 antenatal visits, $67(23.8 \%)$ had 3-4 visits and only 6 (2.1\%) had 5-6 antenatal visits in previous pregnancy.

One hundred and eighty-three $(59.03 \%)$ had home delivering, while 127 (40.97\%) delivered in a hospital.

The decision about the place of delivery was mostly by the husbands in $54.5 \%$ while decision on the place of delivery by the woman herself was only seen in $12.3 \%$ of the respondents. The rest were joined decision between spouses (16.1\%) or the mother in-law (17.1\%) decides.

The time taken by the respondents to travel by motorcycle or motor vehicle to reach the hospital was $<20$ minutes in $42.9 \%$ while $7.1 \%$ of the respondents spent an hour or more before reaching the hospital. The Mean time taken was $24.6 \pm 17.2$ minutes.

Different reasons for home delivery were generated among the respondents who had previous home delivery. Lack of complication in the previous home delivery was the major reason for home delivery in about in $27.3 \%$. This was followed by short labor-delivery interval accounting for about $23.5 \%$ and husband decision seen in $18 \%$. About $15.9 \%$ had no specific reason for the home delivery. Most of this home deliveries were attended or supervised by traditional birth attendance in $115(62.8 \%)$ while 23 (12.6) were attended by a skilled birth attendance at home. The rest were carried out by Mother or mother inlaw.

Majority of the respondents $242(78.1 \%)$ planned to deliver in the hospital in their index pregnancy whereas about 68 (21.9) still prefers to delivery at home. Among the respondent only $19.4 \%$ were on health insurance scheme.

Table 2. Shows Significantly associated test statistics:
Bivariate analysis taking place of delivery as the dependent variable and each of the study variables (Socioeconomic and demographic variables and Antenatal care) as the independent variables revealed that place of delivery is significantly associated with Age (0.005), Religion (0.004), Ethnic group (0.006), Educational level (0.009), Spouse education (0.000), Spouse occupation (0.0001), Type of family (0.001), Parity (0.003), ANC in previous pregnancy (0.000), ANC from gestational age (0.000), Number of ANC visits (0.001), Decision maker about the place of delivery (0.002), Planned place of delivery in index pregnancy (0.000), Health insurance enrollment status (0.001).

Variables found significant at bivariate analysis were entered into the binary logistic regression analysis, with place of delivery as the dependent variable together with the independent variables with a threshold statistical significance level of $<0.05$ and then run. The final model for the intrinsic determinants of the place of delivery among pregnant women attending antenatal clinic at Rano general hospital, Kano consisted of 6 variables; as presented in table 3 . 
Table 2. Antenatal care in determining the place of delivery of the respondents

\begin{tabular}{|c|c|c|c|c|}
\hline \multirow[t]{2}{*}{ Variables } & \multirow[t]{2}{*}{ Frequency (\%) } & \multicolumn{2}{|c|}{ Prev. Place of delivery } & \multirow[t]{2}{*}{ P-value } \\
\hline & & $\begin{array}{l}\text { Home } \\
\text { n (\%) }\end{array}$ & $\begin{array}{l}\text { Hospital } \\
\text { n (\%) }\end{array}$ & \\
\hline \multicolumn{5}{|c|}{ ANC in Previous pregnancy: } \\
\hline Yes & 281(90.6) & $120(42.7)$ & $161(57.3)$ & 0.000 \\
\hline No & $29(9.4)$ & $23(79.3)$ & $6(20.7)$ & \\
\hline \multicolumn{5}{|c|}{ ANC from gestation age in prev: } \\
\hline $1^{\text {st }} \mathrm{TM}$ & $64(22.8)$ & $1(1.6)$ & $63(98.4)$ & 0.000 \\
\hline $2^{\text {nd }} \mathrm{TM}$ & $136(48.4)$ & $34(25)$ & $102(75)$ & \\
\hline $3^{\text {rd }} \mathrm{TM}$ & $81(28.8)$ & $79(97.5)$ & $2(2.5)$ & \\
\hline \multicolumn{5}{|c|}{ Number of ANC visits in prev: } \\
\hline $1-2$ & $208(74.02)$ & $188(90.4)$ & $20(9.6)$ & 0.001 \\
\hline $3-4$ & $67(23.84)$ & $45(67.2)$ & $22(32.8)$ & \\
\hline $5-6$ & $6(2.14)$ & 0 & $6(100)$ & \\
\hline Mean \pm SD, Range: & $1.99 \pm 1.1,5$ & & & \\
\hline \multicolumn{5}{|c|}{ Place of delivery in prev: } \\
\hline Home & $183(59.03)$ & & & \\
\hline Hospital & $127(40.97)$ & & & \\
\hline \multicolumn{5}{|l|}{ Decision maker: } \\
\hline Husband & $169(54.5)$ & & & \\
\hline Myself & $38(12.3)$ & & & \\
\hline Both of us & $50(16.1)$ & & & \\
\hline Mother in-law & $53(17.1)$ & & & \\
\hline \multicolumn{5}{|l|}{ Time taken from home } \\
\hline$<20$ minutes & $133(42.9)$ & $36(27.1)$ & $97(72.9)$ & 0.082 \\
\hline $20-60$ minutes & $155(50)$ & $101(65.2)$ & $54(34.8)$ & \\
\hline$>60$ minutes & $22(7.1)$ & $19(86.4)$ & $3(13.6)$ & \\
\hline Mean \pm SD, Range & $24.6 \pm 17.2,85$ & & & \\
\hline \multicolumn{5}{|c|}{ Attendant during home delivery: } \\
\hline Skilled personnel & $23(12.6)$ & & & $* * *$ \\
\hline TBA & $115(62.8)$ & & & \\
\hline Mother/Mother in law & $45(24.6)$ & & & \\
\hline \multicolumn{5}{|c|}{ Planned place of delivery: } \\
\hline Home & $90(29.03)$ & & & $* 0.000$ \\
\hline Hospital & $220(70.97)$ & & & \\
\hline \multicolumn{5}{|c|}{ Health insurance status: } \\
\hline Yes & $60(19.4)$ & $2(3.3)$ & $58(96.7)$ & $* 0.001$ \\
\hline No & $250(80.6)$ & $69(27.6)$ & & \\
\hline
\end{tabular}


Table 3. Logistic Regression analysis for predictors in determining the place of delivery

\begin{tabular}{lcccc}
\hline \multirow{2}{*}{ Variables } & P-value & $\begin{array}{l}\text { Adjusted } \\
\text { Odds Ratio }\end{array}$ & \multicolumn{2}{c}{$\begin{array}{l}\text { 95\% CI for Adjusted } \\
\text { Odds Ratio }\end{array}$} \\
\cline { 5 - 5 } & & & Lower & Upper \\
\hline Number of ANC visits & 0.001 & 1.856 & 0.924 & 3.730 \\
Educational level & 0.008 & 1.079 & 0.793 & 1.470 \\
Parity & 0.003 & 1.161 & 0.683 & 1.972 \\
ANC from gestational age & 0.013 & 0.552 & 0.345 & 0.884 \\
Planned place of delivery & 0.000 & 9.296 & 3.176 & 27.211 \\
Health insurance enrollment & 0.001 & 0.222 & 0.101 & 0.487 \\
\hline
\end{tabular}

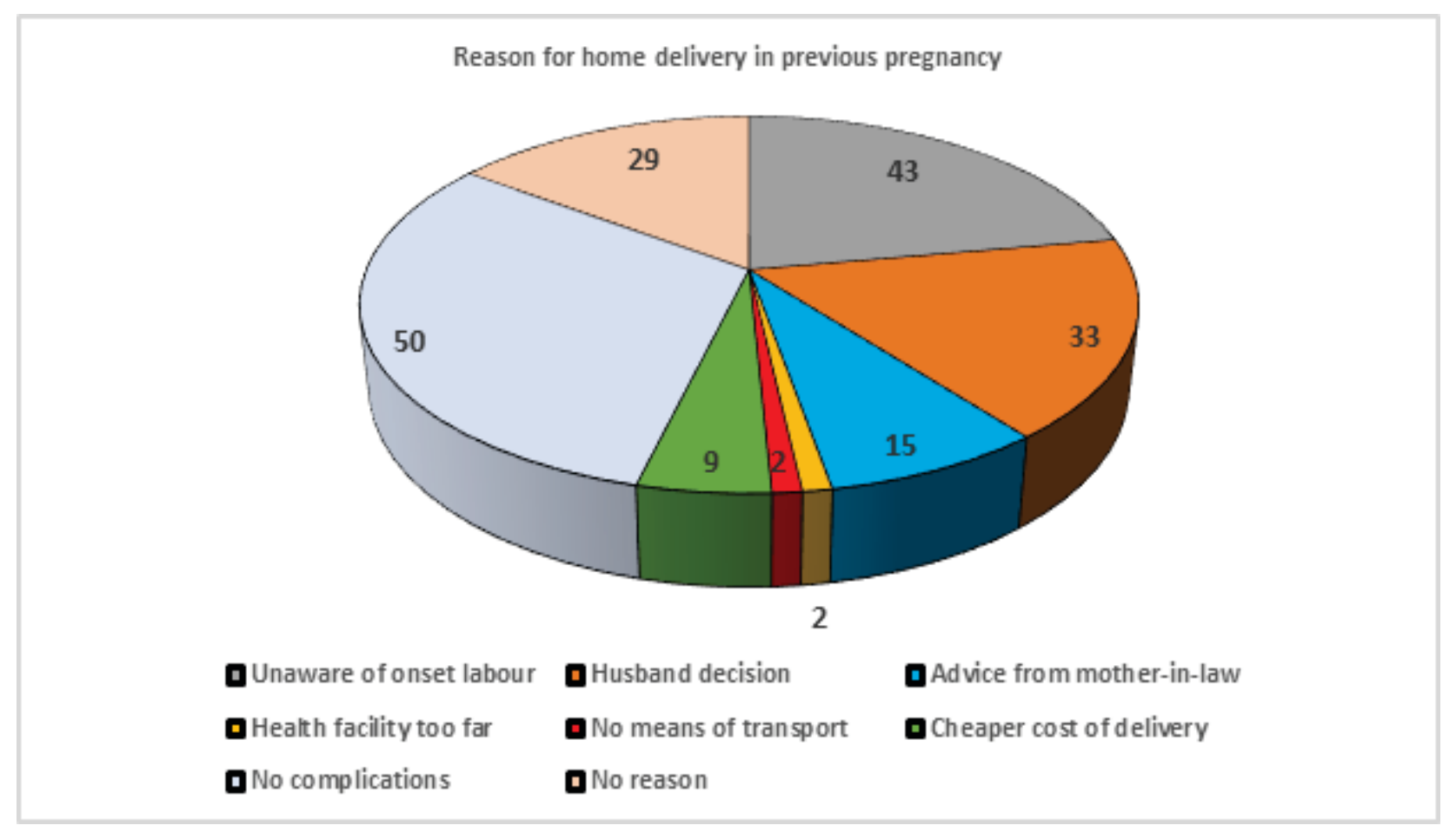

Figure 1. A pie chart showing various reasons for home delivery 


\section{DISCUSSION}

In Nigeria just like most developing countries, a number of women still prefer to deliver at home than to delivery in a health facility with regional variation, the northern part of the country having the highest. ${ }^{1,11}$ The study examined the relationship between mother educational status, spouse educational status, spouse occupation, parity, antenatal attendance in previous delivery, number of antenatal visits, decision maker about place of delivery in determining whether women in a rural setting of Rano LGA of Kano deliver at home or in a health facility.

The results of this study revealed $183(59.0 \%)$ of the total participants had a home delivery. This is lower than 74.1 $\%$ and $70 \%$ who opted out of the process of ANC and delivered at home in the study by Abubakar et al., ${ }^{9}$ and Idris et al., ${ }^{8}$ but is higher compared with study by Kasaye et al., ${ }^{10}$ who found only $25 \%$ of the respondents had home delivery, Egharevba et al., ${ }^{4}$ Envulada et al., ${ }^{1}$ and Dhakal et al., ${ }^{3}$ found only $15 \%, 40 \%$ and $41.9 \%$ delivered with TBA or at home respectively. The difference might be due to different area of resident and region. A lot of contributions had been made to change the awareness of women's utilization of institutional delivery which might result in decreasing home delivery ${ }^{10}$

Educational status of the responding women and husband's level of education was reported as a determinant factor to home delivery from majority of studies done. ${ }^{2,3,11,12}$ Similarly, this study found that majority of the participants have no formal education $45.5 \%$ with only $26.5 \%$ having primary education and this was significantly associated with home delivery $p=0.009$. The lower the level of education the less likely to identify and differentiate between standard and substandard healthcare facilities. The study done in Bagwai by Abubakar et al., ${ }^{9}$ found about $80.5 \%$ have only primary education and below. Education is a key strategy to enhanced health care service utilization and increases the awareness of preventive health care services and the receptive ability for new information thus enables women to discuss and determine the right place for delivery. ${ }^{10}$ Literacy enhanced women's autonomy, confidence and decision making about self as well as children. Educated females are more likely to seek higher quality services and have a greater ability to use health service that offers better care., ${ }^{3,15}$ Study by Dahiru et al., ${ }^{2}$ found that maternal education appears to be the most powerful determinant and predictors of facility delivery. This is also similar to study done by Idris et al., ${ }^{11}$ in Zaria and by Dhakal et al., ${ }^{3}$ in Nepal. Related to the maternal education is the influence of husband's level of education which increases the use of health facility by the woman for delivery. ${ }^{2}$ Having some source of income could imply an improvement in socioeconomic status. ${ }^{5}$ Though delivery services are free in some part of the country including Rano general hospital, there may be an indirect cost involved such as cost of transportation, and sometimes other materials that may be required for delivery, as such an employed woman may overcome this barrier easily relative to unemployed woman. This study found that about $64.5 \%$ of the respondents are unemployed making them unlikely to have safe money to cover their cost of delivery. The husband's occupational status was found to be another determinant of place of delivery in this study as wives of employed husbands tend to deliver at the hospital. Among the $127(40 \%)$ women who had hospital delivery, 68 $(53.5 \%)$ were wives of civil servants. Although the finding in this study is at variance with the study by Idris et $\mathrm{al}^{11}$ who found about $92 \%$ of their husband are engaged in one occupation or the other this may be attributed to the difference in urban and rural settings.

Despite the high number of pregnant women attending the ANC in this study, 29\% still prefer home delivery in their index pregnancy. This finding is not different from other studies where home delivery is the preferred choice of delivery for most pregnant women.

The study in Zaria also found out that adequate ANC attendance did not significantly influence hospital delivery. ${ }^{11}$ This study found that about $90 \%$ of the participants attended ANC at least once during their last pregnancy yet only $40.97 \%$ delivered in the hospital. Studies by Berhan et al., ${ }^{13}$ and Choe et al., ${ }^{14}$ also found no association between ANC and subsequent delivery in a health facility. The high ANC utilization and low health facility delivery in this study conform to findings from other studies conducted by Boah et al., ${ }^{5}$ in Ghana who also reported that women who had more than four ANC visits were more likely to delivery with a skilled attendant than those with fewer visits. ${ }^{5,15}$ Unaware of onset of labor (short interval between onset and delivery) and no complication in their previous home deliveries as seen in study by Boah et $a l .,{ }^{5}$ and husbands decision as to place of delivery reported by Yegezu et al., ${ }^{16}$ and Boah et al., ${ }^{5}$ were the major causes of home delivery in this study. This in 
contrast to other studies in some part of African countries were distance to health facility and non-friendly attitude of care giver were the major reason given for opting for home delivery with TBA or a relative. ${ }^{17,18}$ In a study by Kasaye et al., ${ }^{10}$ found that perceived lack of privacy during ANC increases the odds of home delivery given the reason that most women reported that they fear to exposed their reproductive organs during delivery, ${ }^{10}$ though not found to be a reason for home delivery in this study.

In a study by Idris et al., ${ }^{11}$ and Shehu et at., ${ }^{15}$, observed that women residing in the rural areas are more likely to deliver at home and less likely to be attended by trained medical personnel, possibly because of strong attachment to cultural values and beliefs. ${ }^{15}$ This study also has similar findings were more of the home deliveries were by a TBA $(62.8 \%)$ or unskilled person $(24.6 \%)$. Home delivery especially with unskilled attendant are associated with increased risk of prenatal and maternal mortalities. This brings to the fore and the ongoing debate of training of TBAs so that they can be better skilled at recognizing some obstetric danger signs and hasten referral of such cases to better equipped health facilities. ${ }^{15}$

There was a positive significant association between age, religion, family type and ethnicity and place of delivery in this study. Though a study from Nepal by Dhakal et al., ${ }^{3}$ found no significant association between age, ethnicity and family type with place of delivery probably because of different study region and cultural differences.

Findings from this study revealed that women with more than four children are likely to delivery at home compare to lesser parity women. This could be thought to be due to experience with childbirth from previous deliveries and this may contribute to her decision making process as to whether to deliver at home or at a health facility. ${ }^{5}$ A woman delivering for the first time may lack self-confidence and consider the delivery very challenging and anticipate unforeseen complications. ${ }^{5}$ A similar studies done in Nigeria by Dahiru et a.l., ${ }^{2}$ Egharevba et al., ${ }^{4}$ and in Nepal by Dhakal et al., ${ }^{3}$ reported an inverse relationship between parity and use of facility delivery. A study by Boah et al., ${ }^{5}$ found that women with higher parity five and more may consider herself at high risk of birth complications due to the deliveries and thus recourse to a health facility for delivery.

In this study, having a valid health insurance was associated with health facility delivery as was a finding in a studies done by Dahiru et al., ${ }^{2}$ in Nigeria and Boah et al., ${ }^{5}$ in Ghana who reported high utilization of health facility delivery with possession of a health insurance.

\section{CONCLUSION}

This study has shown that there is still high rate of home delivery among antenatal clinic attendees. This home delivery is usually preferred to hospital delivery by their husbands and mother in-laws as they consider it to be safe and more convenient. There is therefore need to educate women on early signs of labor and address the importance of supervised delivery in a health care institution to prevent complications which may increase the maternal morbidity and mortality.

\section{REFERENCES}

1. Envuladu EA, Agbo HA, Lassa S, Kigbu JH, Zoakah AI. Factors determining the choice of a place of delivery among pregnant women in Russia village of Jos North, Nigeria: achieving the MDGs 4 and 5. Int J Med Biomed Res. 2013; 2(1):23-27

2. Dahiru T, Oche OM. Determinants of antenatal care, institutional deleivry and postnatal care services utilization in Nigeria. PanAfrican Medical Journal. 2015; $21: 321$ doi:10.11604/pamj.2015.21.321.6527

3. Dhakal P, Shrestha M, Baral D, Pathak S. Factors Affecting the Place of Delivery among Mothers Residing in Jhorahat VDC, Morang Nepal. IJCBNM. 2018; 6(1): 2-11

4. Egharevba J, Pharr J, Van Wyk B, Ezeanolue E. Factors Influencing the Choice of Child Delivery Location among Women Attending Antenatal Care Services and Immunization Clinic in Southeastern Nigeria. International Journal of $\mathrm{MCH}$ and AIDS. 2017; 6(1): 82-92

5. Boah M, Mahama AB, Ayamga EA. They receive antenatal care in health facilities, yet do not deliver there: predictors of health facility delivery by women in rural Ghana. BMC Pregnancy and Childbirth. 2018; 18:125. https://doi.org/10.1186/s12884-018-1749-6 NDHS 2018

7. Dixit P, Khan J, Dwivedi LK, Gupta A. Dimensions of antenatal care service and the alacrity of mothers towards institutional delivery in South and South East Asia. PLoS ONE. 2017; 12(7): e0181793. https://doi.org/10.1371/journal.pone.0181793

8. Fagbamigbe AF, Idemudia ES. Barriers to antenatal 
care use in Nigeria: evidence from non-users and implications for maternal health programming. BMC Pregnancy and Childbirth. 2015; 15: 95. DOI 10.1186/S12884-015-0527-y

9. Idris $\mathrm{SH}$, Sambo MN, Ibrahim MS. Barriers to utilization of maternal health services in a semiurban community in northern Nigeria: The clients' perspective. Nigerian Medical Journal. 2013; 54(1): 27-32

10. Abubakar S, Adamu D, Hamza R, Galadima JB. Determinant of Home Delivery amongWomen attending Antenatal Care in Bagwai Town, Kano Nigeria. African Journal of Reproductive Health. 2017; 21(4): 74.

11. Kasaye HK, Endale ZM, Gudayu TW, Desta MS. Home delivery among antenatal care booked women in their last pregnancy and associated factors: community-based cross sectional study in Debremarkos town, North West Ethiopia. BMC Pregnancy and Childbirth. 2017;17:225

12. Idris SH, Gwarzo UMD, Shehu AU. Determinant of Place of Delivery among Women in a Semi-Urban Settlement in Zaria, Northern Nigeria. Annal of African Medicine. 2006; 5(2):68-72

13. Olarinoye AO, Adesina KT, Aderibigbe SA, Akande TM, Fawole AA. Sociodemographic Characteristics and Pregnancy outcome of Referred and Booked Parturient in a Nigerian Teaching Hospital. 2018; 45(1): 23-31

14. Berhan Y, Berhan A. Antenatal Care as a Means of Increasing Birth in the Health Facility and Reducing Maternal Mortality: A Systematic Review. Ethiop J Health Sci. 2014; 24(0 suppl): 93104

15. Choe SA, Kim J,Kim S, Park Y, Kullaya SM, Kim C. Do antenatal care visits always contribute to facility-based delivery in Tanzania? A study of repeated cross-sectional data. Health Policy and Planning. 2016; 31(3): 277-284

16. Shehu CE, Ibrahim MTO, Oche MO, Nwobodo EI. Determinant of place of delivery: A comparison between an urban and rural community in Nigeria. Journal of Public Health and Epidemiology. 2016; 8(6): 91-101

17. Yegesu RT, Kitili SB. Assessment of Factors Affecting Choice of Delivery Place among Pregnant Women in Jimma Zone, South West Ethiopia: Cross
Sectional Study. Journal of Women's Health Care. 2014; 4(1): 211

18. Some TD, Sombie I, Meda N. Women's perceptions of homebirth in two rural medical districts in Burkina Faso: a quantitative study. Can Stud. Popul. 2011; 38(1-2): 83-98

19. Onta S, Choulagai B, Shrestha B, Subedi N, Bhandari GP, Krettek A. Perceptions of users and providers on barriers to utilizing skilled birth care in mid- and far-western Nepal: a qualitative study. Global Health Action. 2014; 7: 24580. 